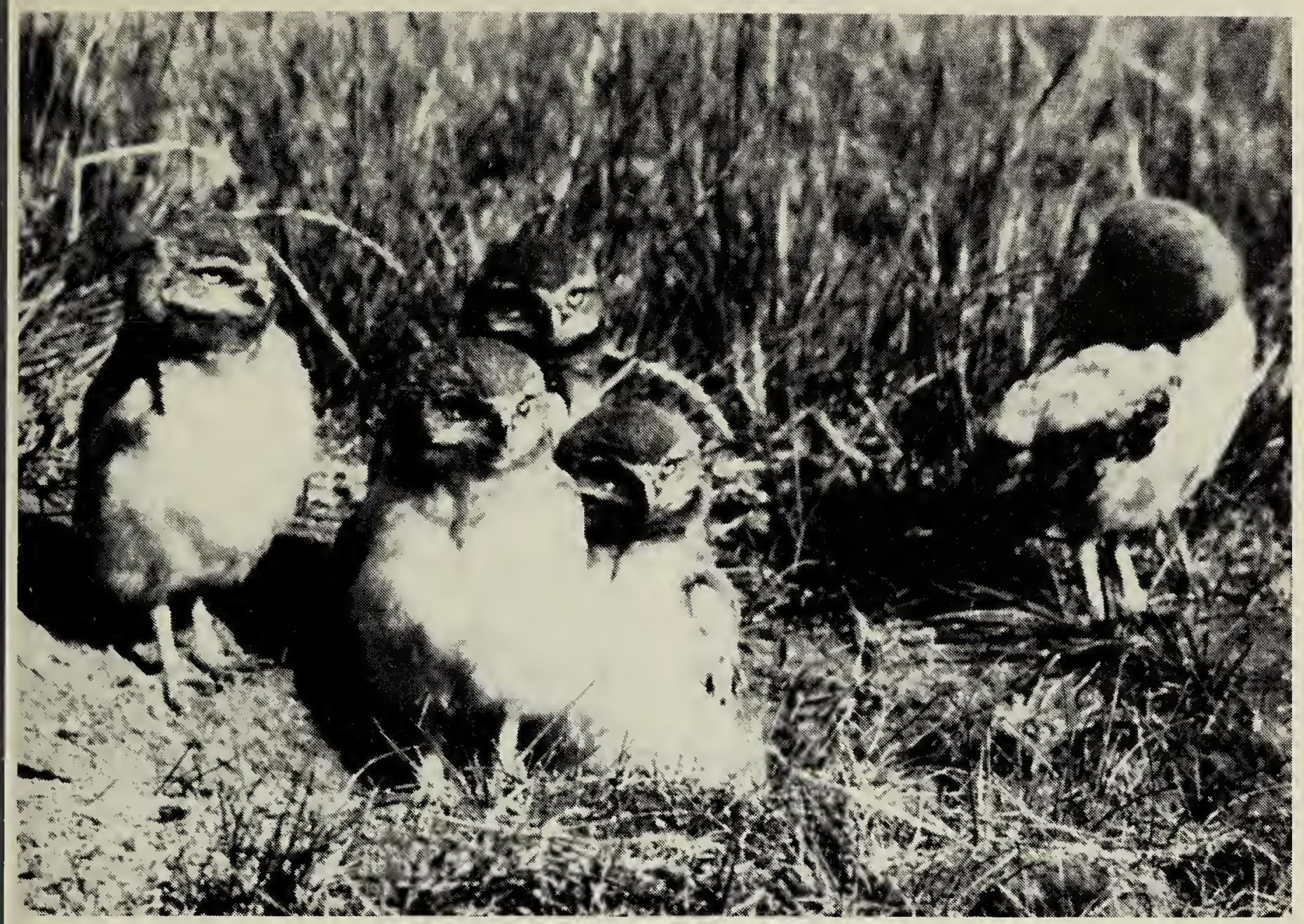

\title{
EFFECTS OF SOME INSECTICIDES ON PRODUCTIVITY OF BURROWING OWLS
}

PAUL C. JAMES, Museum of Natural History, Saskatchewan Culture and Recreation, Wascana Park, Regina, Saskatchewan, S4P 3V7 and GLEN A. FOX, Wildlife Toxicology and Surveys Branch, Canadian Wildlife Service, Environment Canada, Ottawa, Ontario. K1A OE7

\section{Introduction}

Damage to grassland by grasshoppers in western Canada has been noted ever since the days of the early explorers. These insects can cause significant losses of cereal and forage crops; this has led to heavy reliance on chemical control to reduce grasshopper damage. The magnitude of current chemical use is illustrated by the fact that an estimated 7 - 8 million acres were sprayed for grasshopper control in Saskatchewan alone in 1986 (L. Harris, Sask. Agriculture).
The Burrowing Owl has been designated a threatened species in Canada by the Committee on the Status of Endangered Wildlife in Canada (COSEWIC). Two-thirds of the Canadian population may breed in Saskatchewan. Although a progressive decline in numbers has been described in recent decades, the causes remain to be determined. ${ }^{9}$ Haug found that insects comprised $93 \%$ of the 1,842 prey items identified at Saskatchewan nest sites in 1982 and 1983; grasshoppers accounted for $75 \%$ of these insects. ${ }^{6}$ Grasshoppers make up about $70 \%$ of the 
total diet of these birds. In Haug's study, $60 \%$ of flights from the nest burrow were within $50 \mathrm{~m}$ and $90 \%$ were within $400 \mathrm{~m}^{6}{ }^{6}$

In 1986 a pilot study was carried out to determine the impact of grasshopper spraying on the reproductive success of Burrowing Owls in Saskatchewan.

\section{Study area and Methods}

To determine the effects of chemical grasshopper control the following study was designed. Study areas were selected using the predicted intensity of grasshopper infestation and known Burrowing Owl density. Within these study areas, active nest burrows were located. Reproductive performance was monitored and the history of insecticide application obtained from the land manager and rural municipalities. The treatment groups were then chosen a posteriori based upon the relative number of burrows which were exposed to the various insecticides. Although six insecticides were used, a sufficient number of burrows for statistical analysis was available only for carbaryl and carbofuran treated sites.

The choice of study areas was determined by two factors:

(1) the density of nesting Burrowing Owls within the area had to be high enough to generate a satisfactory sample size with minimal travel

(2) the expected grasshopper infestation had to guarantee that spraying would occur.

Two areas were selected

(1) the heavily cultivated area surrounding Regina, an area expected to have moderate to very severe grasshopper infestation

(2) an area comprised predominantly of rangeland, near Val Marie which was predicted to have a moderate infestation.

In these study areas, active Burrowing Owl nests were located during late May and early June 1986. Repeated visits were made to count the number of young visible above ground. Young were captured, banded, weighed and measured.

Landowners and land managers provided details of grasshopper spraying including the date, location, and chemical applied. Any spraying that occurred within $400 \mathrm{~m}$ of an active nest burrow was regarded as a potential exposure (from the findings of Haug6).

The statistical probablilites of differences observed between nests treated with carbaryl and/or carbofuran and those not receiving any chemical exposure were determined using a permutation test. ${ }^{2}$ All possible pairwise comparisons among the treatment groups were permuted 1000 times and the proportion of times the permuted data gave a difference as extreme as the observed difference provided a measure of significance. Since nest burrows were clustered on a number of different farms, a "farm effect" was allowed for in all analyses by permuting the farm totals rather than the values for the individual burrows. Since no "farm effect" was detected for any parameter, its inclusion means that this analysis is highly conservative.

\section{Results}

The details of insecticide exposure on the two study areas are summarized in Table 1 . Only 23 of the 99 nesting pairs located on the two study areas were not subjected to at least one spray event within $400 \mathrm{~m}$ of their nest burrow in 1986 . Seventy percent of all exposures were within $50 \mathrm{~m}$ of the nest burrow. Forty-nine percent of burrows were exposed on more than one occasion. Of the 64 burrows studied near Regina, 97\% were exposed at least once within $400 \mathrm{~m}$, in marked contrast to only $40 \%$ of the 35 burrows studied in the Val Marie area. Three roadside applications by municipalities in the Regina area exposed a total of 48 burrows ( $77 \%$ of the total exposed) on 15 farms. Similarly, two roadside applications by municipalities in the Val Marie area ex- 
Table 1. DETAILS OF INSECTICIDE SPRAYING IN TWO BURROWING OWL STUDY AREAS, 1986

Total Nests Studied

Young observed at Nest

Not sprayed within $400 \mathrm{~m}$

Sprayed within $50 \mathrm{~m}$

Sprayed within $400 \mathrm{~m}$

Sprayed two or more times

Sprays before young seen

Sprays after young seen
Farmland (Regina)

No.

$\begin{array}{rr}64 & \\ 50 & 78 \\ 2 & 3 \\ 49 & 77 \\ 62 & 97 \\ 49 & 77 \\ 145 & 94 \\ 10 & \end{array}$

Grassland (Val Marie)

No.

$\%$

35

$11 \quad 31$

$21 \quad 60$

$4 \quad 11$

$14 \quad 40$

$0 \quad 0$

92

Table 2. IMPACT OF CARBOFURAN AND CARBARYL GRASSHOPPER SPRAYS ON BURROWING OWL REPRODUCTIVE SUCCESS.

Number of nests is given in parentheses.

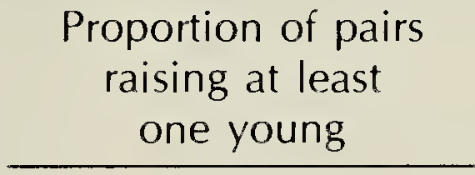

$74 \%(23)$

$77 \%(30)$

$50 \%(18)$

$76 \%(50)$

$77 \%(30)$

$38 \%(13)^{\mathrm{ab}}$
Maximum number of young observed per nest

$3.78(23)$

$3.82(28)$

$2.44(18)$

$3.80(50)$

$3.30(30)$

$1.77(13)^{\mathrm{cd}}$

$a=P=0.041$ when compared with not exposed

$\mathrm{b}=\mathrm{P}=0.092$ when compared with carbaryl

$c=P=0.025$ when compared with not exposed

$d=P=0.097$ when compared with carbaryl 
posed 12 burrows (86] on 4 properties. Of the 61 exposed burrows at which young were observed above ground on one or more visits, $82 \%$ were only exposed before the young were first observed. Thirteen exposure events occurred before the young were observed above ground for every one occurring after.

Six different insecticides were applied within $400 \mathrm{~m}$ of one or more nest burrows. Carbofuran (Furadan), carbaryl (Sevin), and chlorpyrifos (Lorsban) accounted for $35 \%, 35 \%$, and $15 \%$ of the applications, respectively. The other insecticides used were deltamethrin, malathion and methamidophos. The mechanism of toxic action of these agents, with the exception of deltamethrin, is the inhibition of the enzyme acetylcholinesterase, normal activity of which is essential for normal nervous system function in insects, birds and mammals.

The productivity of pairs exposed to carbaryl and/or carbofuran is summarized in Table 2. One or more exposures to carbaryl within 50 or $400 \mathrm{~m}$ of the nest burrow had little effect on productivity. In marked contrast, exposure to carbofuran within $50 \mathrm{~m}$ of the nest burrow was associated with a $54 \%$ reduction in the number of young per nest ( $P$ 0.05) and a $50 \%$ reduction in the proportion of pairs that raised one or more young ( $P$ 0.05) relative to the $50 \mathrm{~m}$ control. Since no pairs were exposed to carbofuran alone within $400 \mathrm{~m}$, the productivity of those exposed to both carbaryl and carbofuran was compared to those exposed only to carbaryl. The productivity of pairs exposed to both agents was $35-36 \%$ lower than those exposed to carbaryl alone ( $\mathrm{P} \quad 0.10$ ).

The hazard posed by direct spraying of nest burrows is illustrated by a comparison of the reproductive performance of owls nesting in three pastures near Regina (Table 3). One pasture containing 5 active nests was sprayed aerially on 17 June with carbofuran, another containing 10 active nests was aerially sprayed with carbaryl, while another containing 14 active nests was not sprayed with any agent. No young or adults were ever seen above ground on seven successive site visits over a period of four weeks after the burrows were sprayed with carbofuran. Some of these adults may have perished since the usual behavior of adults after nest failure is to remain at or near the nest site. All five burrows sprayed with carbofuran were ex-

\section{Table 3. REPRODUCTIVE SUCCESS OF BURROWING OWLS IN THREE PASTURES NEAR REGINA}

\begin{tabular}{|c|c|c|c|}
\hline & Carbofuran* & Carbaryl* & None \\
\hline $\begin{array}{l}\text { Number of active } \\
\text { nest burrows at time } \\
\text { of spraying }\end{array}$ & 5 & 10 & 14 \\
\hline $\begin{array}{l}\text { Proportion of nests } \\
\text { producing one or more } \\
\text { young }\end{array}$ & $0 \%^{a, b}$ & $70 \%$ & $93 \%$ \\
\hline $\begin{array}{c}\text { Max. number of young } \\
\text { per nesting attempt }\end{array}$ & $0^{c}$ & $2.9^{\mathrm{d}}$ & 4.3 \\
\hline
\end{tabular}

\footnotetext{
* Aerially sprayed with insecticide. Values given are means.

$\mathrm{a}=\mathrm{P} 0.005$ when compared with no spray, Fisher's Exact Test

$\mathrm{b}=\mathrm{P} 0.025$ when compared with carbaryl, Fisher's Exact Test

$c=P \quad 0.001$ when compared with no spray, Mann-Whitney Statistic

$\mathrm{d}=\mathrm{P} 0.05$ when compared with no spray, Mann-Whitney Statistic
} 
cavated between 4 and 16 July 4 . A single adult was captured in each of three burrows, an intact egg and eggshells were found in another, and the remains of small chicks were found in another which had been previously dug up by a fox. Affected adults may have sought shelter in other unoccupied burrows and died there. If they died outside the burrow it is likely the carcasses would disappear rapidly. ${ }^{1}$

\section{Conclusions and Recommendations}

In areas and years of moderate to severe grasshopper infestation, Burrowing Owls nesting in Saskatchewan are frequently exposed to insecticidal agents. It is apparent that some of these agents have a greater impact on reproduction than others. There was a difference in the frequency of exposure between the two study areas which was consistent both with the severity of the predicted infestation and the greater crop area at risk to grasshopper damage in the Regina study area.
The relative toxicity to birds of insecticides currently registered for grasshopper control is shown in Table 4. Although these agents are roughly equivalent in effectiveness at the labelled application rates, their toxicities to the Mallard (one of the few species in which all these chemicals have been tested) vary greatly; carbofuran is 10,000 times more toxic than deltamethrin. We do not know the sensitivity of the Burrowing Owl relative to the Mallard.

Since the various insecticides applied are roughly equal in their effectiveness, differences in reduction of owl food between agents is not expected. The effects on productivity observed with carbofuran suggest that these impacts are not the result of reduction of the food supply, but that this insecticide is particularly toxic to Burrowing Owls. This is further substantiated by the marked difference in impact between the combination of carbaryl and

\section{Table 4. RELATIVE AVIAN TOXICITY OF CHEMICALS REGISTERED FOR GRASSHOPPER CONTROL IN 1986. Agents are listed in order of decreasing toxicity, based on data for the Mallard.}

Active Ingredient

\begin{tabular}{lcccc} 
& $\begin{array}{c}\text { LD } 50^{*} \\
\mathrm{mg} / \mathrm{kg} \text { b.w. }\end{array}$ & & LD 50 Units/Acre & $\begin{array}{c}\text { Minimum Cost/Acre } \\
\text { Canadian } \$ \$^{* *}\end{array}$ \\
\cline { 1 - 1 } \cline { 5 - 5 } Carbofuran & 0.5 & & 106,000 & \\
Methamidophos & 8 & & 27,625 & $\$ 2.45$ \\
Dimethoate & 50 & & $1,728-3,940$ & $\$ 4.71$ \\
Chlorpyrifos & 75 & & $1,467-2,240$ & $\$ 1.90$ \\
Azinphos-methyl & 136 & & $441-1,185$ & $\$ 3.29$ \\
Malathion & 1487 & & 230 & $\$ 2.58$ \\
Carbaryl & 2564 & $88-203$ & $\$ 4.31$ \\
Deltamethrin & 4640 & 0.6 & $\$ 4.23$ \\
\hline
\end{tabular}

*. = Toxicity of active ingredient for the Mallard; for example $50 \%$ of the Mallards eating 0.5 milligrams of carbofuran for each kilogram of their own body weight have been found to die in laboratory experiments - LD50 is the lethal dose for $50 \%$ of the population.

** Product costs (in 1985) and toxicity of commercial product at recommended application rates derived from figures presented in "Grasshopper Forecast in Saskatchewan - 1986" (Sask. Agriculture, Regina) 
carbofuran relative to that of carbaryl alone. The increased impact with carbofuran exposures at 0 and $50 \mathrm{~m}$ relative to those at $400 \mathrm{~m}$ suggests an increasing hazard with proximity of the application to the burrow.

The majority of insecticides were applied between 10 and 30 June while the female Burrowing Owls were incubating eggs or brooding small young. The carbofuran-associated impacts are therefore thought to be the result of alterations in parental behavior. Laughing Gulls dosed with parathion spent significantly less time incubating in the 72 hours following dosing than did gulls dosed with corn oil. ${ }^{10}$ Female European Starlings exposed to sufficient organophosphate insecticide to reduce the activity of the brain enzyme cholinesterase by $50 \%$ made significantly fewer sorties to feed their young and were away from their nest boxes for longer periods of time than were controls. ${ }^{5}$ Their nestlings also lost significantly more weight. These experimental studies suggest that cholinesterase-inhibiting insecticides can alter amount of time spent incubating the eggs or brooding and/or feeding the chicks. The chicks may also be poisoned by insecticide-contaminated food provided by the adults.
The total net economic benefit accruing to Saskatchewan wheat growers from chemical grasshopper control over the period 1980 to 1985 has been estimated at $\$ 161$ million. ${ }^{7}$ Despite their extensive use, insecticides have not reduced the frequency or intensity of regional grasshopper infestations; they have merely conferred a measure of crop protection or salvage. ${ }^{8}{ }^{4}$ Weather, parasites, disease, and natural predators have been the primary instruments reducing populations. While it is known that Burrowing Owls and numerous other birds consume large numbers of grasshoppers and other insect pests, the contribution of birds, relative to other controlling factors is not known. Nevertheless, it would benefit the farmer to apply those insecticides with the lowest avian toxicity, thereby protecting his crop while minimizing undesireable impacts on local birds that help the farmer by eating grasshoppers.

Our carbaryl and carbofuran findings suggest that the relative impact on reproductive success of Burrowing Owls reflects the acute toxicity of the principal insecticides available for grasshopper control as judged by the LD50 for Mallards (the lethal dose for $50 \%$ of the population). If so, then highly toxic agents such as carbofuran should not be applied

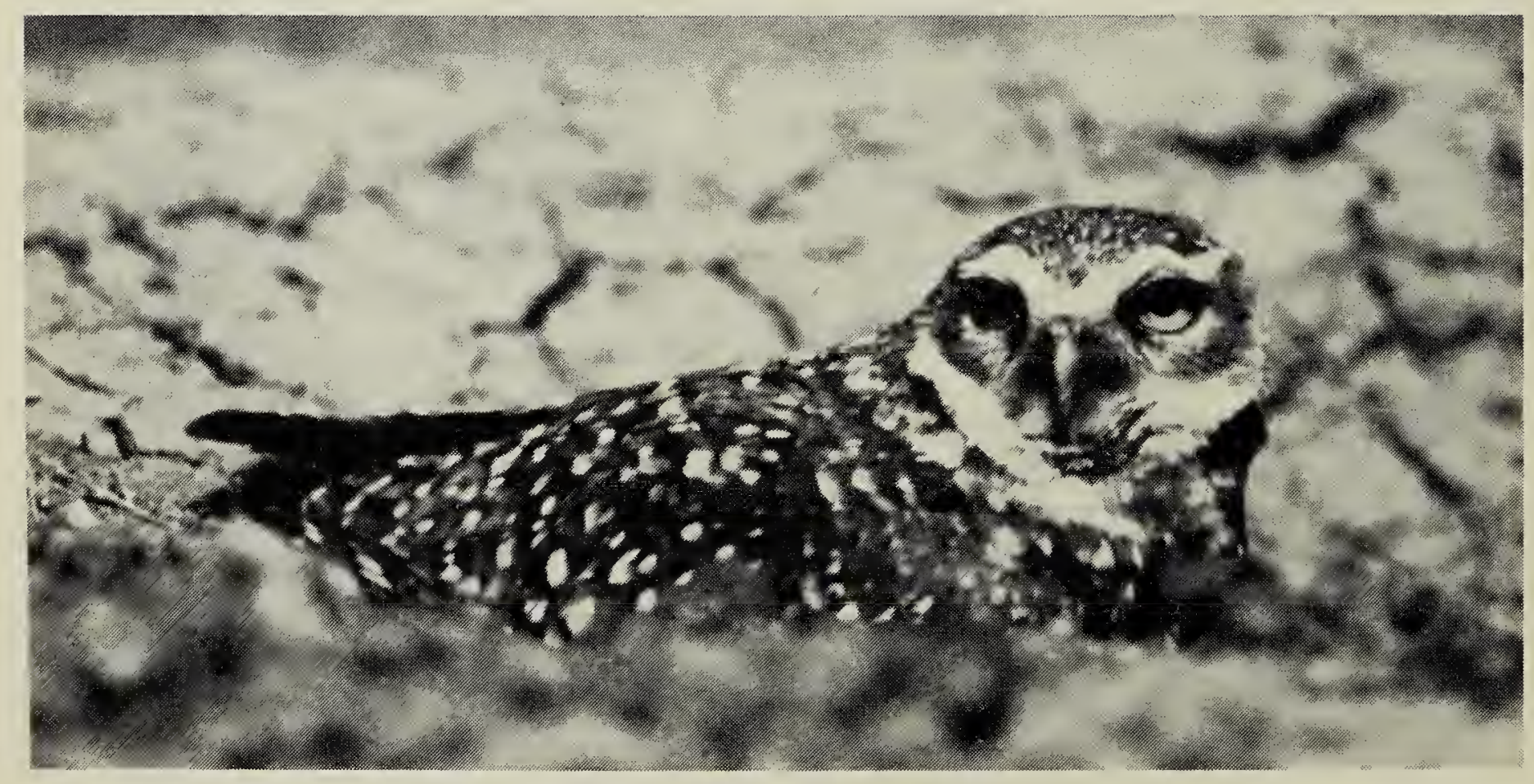


within $400 \mathrm{~m}$ of active Burrowing Owl nests. Active Burrowing Owl nests should not be directly sprayed with any insecticide. The relative toxicity to beneficial birds should also be taken into consideration by government agencies when recommending insecticides for grasshopper control and in choosing those for which the cost is to be subsidized. Similarly, municipalities (responsible for exposure of over $75 \%$ of the burrows in both study areas) should choose insecticides with the lowest toxicity to nontarget organisms for roadside and other applications. Finally, since $87 \%$ of the known Burrowing Owl nesting sites in Saskatchewan are on private land, ${ }^{3}$ it is vitally important that land owners and land managers are made aware of the hazards insecticides pose to this bird. The Burrowing $\mathrm{OWl}$ is designated as a threatened species, and the Canadian population is a significant component of the continental population. Since the Burrowing Owl is predominantly a bird of the grasslands, its distribution is very similar to that of grasshoppers and grain farms. As long as chemical agents are used for grasshopper control, there is potential for Burrowing Owls to be exposed.

\section{Acknowledgments}

We gratefully acknowledge the essential cooperation and assistance of the following landowners and managers: Baker, Bardutz, Chandler, Cherpin, Dixon, Donovan, Dukat, Euteneier, Evesque, Fahlman, Laturnes, Loughren, Martin, Noll, Pahlicheik, Parker, Pedersen, Perrault, Patsy, Ried, Sattler, Stevenson, Turner, Thibeault, and Way. Excellent field assistance was provided by M. Hey and T. Ethier. B. Haug and A. Didiuk were also most helpful and supportive throughout the study. B. Collins, senior biostatistician for the Canadian Wildlife Service, was responsible for the design, conduct, and interpretation of the statistical analyses. P. Mineau and K. Freemark provided constructive comments on design and interpretation of the study. Funding for this work was provided by the Pestfund program of Environment Canada.

1 BALCOLM, R. 1986 Songbird carcasses disappear rapidly from agricultural fields. Auk 103:817-820.

2 CRUMP, K.S. AND R.B.HOWE 1979. A small sample study of permutation tests for detecting teratogenic effects. Ebon Research Systems, Washington, D.C.

3 DIDIUK, A.B. 1986. Burrowing Owl nesting in Saskatchewan: distribution and land tenure. Unpublished report for the Saskatchewan Natural History Society.

${ }^{4}$ GAGE, S.H. AND M.K. MUKERJIE 1978. Crop losses associated with grasshoppers in relation to economics of crop production. J. Econ. Entomol. 71:487-498.

5 GRUE, C.E., G.V.N. POWELL and M.J. MCCHESNEY 1982. Care of nestlings by wild female starlings exposed to an organophosphorus pesticide. J. Appl. Ecology 19:327-335.

6 HAUG, E.A. 1985. Observations on the breeding ecology of burrowing owls in Saskatchewan. Unpubl.M.Sc Thesis, University of Saskatchewan, Saskatoon.

7 MADDER, D.J. and M. STEMEROFF 1986. The economics of insect control on wheat, corn and canola in Canada, 1980-1985. Entomological Society of Canada.

8 RIEGERT, P.W. 1968. A history of grasshopper abundance surveys and forecasts of outbreaks in Saskatchewan. Mem. Entomol. Soc. Canada No. 52

9 WEDGWOOD, J.A. 1978. Status report on burrowing owl (Athene cunicularia) in Canada. Prepared for Committee on the Status of Endangered Wildlife in Canada (COSEWIC).

10 WHITE, D.H., C.A. MITCHELL and E.F. HILL 1983. Parathion alters the incubation behavior of laughing gulls. Bull. Environ. Contam. Toxicol. 31:93-97. 